\title{
Left ventricular assist device as a bridge to surgery in postinfarction ventricular septal defect
}

\author{
Antonis A. Pitsis, MD, FETCS, FESC, ${ }^{a}$ Timotheos G. Kelpis, MD, ${ }^{a}$ Aikaterini N. Visouli, MD, ${ }^{a}$ Georgios Bobotis, MD, ${ }^{b}$ \\ Gerasimos S. Filippatos, MD, FCCP, FESC, ${ }^{\mathrm{c}}$ and Dimitrios T. Kremastinos, MD, FESC, FACC, ${ }^{\mathrm{c}}$ Thessaloniki and Athens, \\ Greece
}

\section{Clinical Summary}

A 43-year-old man was transferred to Thessaloniki Heart Institute 15 days after an anterior wall myocardial infarction. He presented in cardiogenic shock with reinfarction and a large left-to-right shunt with intra-aortic balloon pump (IABP) and inotropic support. Physical examination revealed a loud holosystolic murmur that was best heard at the left lower sternal border. Electrocardiography findings were consistent with an anterior myocardial infarction. Transesophageal echocardiography demonstrated a large anterior postinfarction ventricular septal defect (PVSD) (Figure 1, A). Coronary angiography showed an ostial occlusion of the left anterior descending artery. The patient was transferred to the operating theater; a median sternotomy was performed, and the pericardial cavity was entered. An extensive hematoma was visualized in the anterior wall of the left ventricle and the free wall of the right ventricle (Figure $2, A$ ). It became immediately apparent that a primary repair was at a high risk of failure because of potential dehiscence of the edematous tissue. Therefore, the patient was placed on mechanical circulatory support, and surgery was deferred to a later stage when the quality of infarcted tissue improved. The Levitronix Centrimag (Zurich, Switzerland) extracorporeal left ventricular assist device (LVAD) was used. Inflow was established in the left atrium (Figure $1, B)$, and outflow was established in the ascending aorta. The IABP was removed. The LVAD functioned consistently at a flow rate of $5 \mathrm{~L} / \mathrm{min}$, and the patient recovered from cardiogenic shock. Four days later the patient underwent PVSD repair by an infarct exclusion technique ${ }^{1}$ (Figure $2, B$ ), LVAD explantation, and IABP reinsertion from the groin. The patient tolerated the procedure well. The IABP was removed 3 days later, and the patient was discharged on postoperative day 10 . At 1 year, the patient remained alive and well, and transthoracic echocardiography demonstrated no residual PVSD (Figure 1, C).

From the Thessaloniki Heart Institute, St Luke's Hospital, ${ }^{\mathrm{a}}$ Thessaloniki, Greece; Cardiology Department, Papageorgiou Hospital, ${ }^{\mathrm{b}}$ Thessaloniki, Greece; and Cardiology Department, Athens University Hospital Attikon, ${ }^{\mathrm{c}}$ Athens, Greece.

Received for publication Nov 5, 2007; accepted for publication Dec 4, 2007.

Address for reprints: Antonis A. Pitsis, MD, FETCS, FESC, Thessaloniki Heart Institute, St Luke's Hospital, Panorama, 55236, Thessaloniki, Greece (E-mail: apitsis@otenet.gr).

J Thorac Cardiovasc Surg 2008;135:951-2

$0022-5223 / \$ 34.00$

Copyright (C) 2008 by The American Association for Thoracic Surgery doi:10.1016/j.jtcvs.2007.12.004

\section{Discussion}

PVSD, although less frequent in the reperfusion era, remains a serious complication of acute myocardial infarction with a high mortality. Mechanical circulatory support as a bridge to transplant in extreme cases of PVSD has been infrequently reported in the literature. ${ }^{2-5}$ Faber and colleagues ${ }^{2}$ reported the successful use of an implantable LVAD (HeartMate [Thoratec Corporation, Pleasanton, Calif] and Novacor [WorldHeart Corporation, Ottawa, Ontario, Canada] devices) as a bridge to transplant in 2 patients in cardiogenic shock after PVSD repair. Samuels and colleagues ${ }^{3}$ described the use of the Abiomed BVS5000 ventricular assist device (Abiomed, Inc, Danvers, Mass) with biatrial cannulation for the uncorrected PVSD as a bridge to transplant. High right-to-left shunting across the ventricular septum has been reported to cause hypoxic brain injury in patients with PVSD placed on a HeartMate ILVAD as a bridge to transplant. In this case the inflow cannula was placed in the left ventricle. ${ }^{4}$ Meyns and colleagues ${ }^{5}$ reported the use of the Hemopump (Johnson \& Johnson Interventional Systems, Rancho Cordova, Calif) axial flow device as a bridge to transplant in 2 patients with PVSD, and both patients experienced lethal pump failure. Examination of the device at autopsy disclosed necrotic material clogging the catheter system. In our patient, the blood was withdrawn from the left atrium, avoiding the deleterious effect of shunt reversal ${ }^{4}$ or clogging of the device with necrotic myocardium. ${ }^{5}$ A novel approach to this entity includes the use of the Levitronix Centrimag short-term LVAD as a bridge to surgery without attempting an immediate high-risk repair. The rationale behind this approach is to avoid operating on fresh infarct and to establish prompt circulatory control to support end-organ function. To the best of our knowledge, this the first report in the literature in which an LVAD has been used successfully as a bridge to surgery after PVSD. Our experience suggests that this strategy serves as an alternative treatment option.

\section{References}

1. David TE, Dale L, Sun Z. Postinfarction ventricular septal rupture: repair by endocardial patch with infarct exclusion. $J$ Thorac Cardiovasc Surg. 1995; 110:1315-22.

2. Faber C, McCarthy PM, Smedira NG, Young JB, Starling RC, Hoercher KJ. Implantable left ventricular assist device for patients with postinfarction ventricular septal defect. J Thorac Cardiovasc Surg. 2002;124:400-1.

3. Samuels LE, Entwistle JC 3rd, Holmes EC, Parris T, Wechsler AS. Mechanical support of the unrepaired postinfarction ventricular septal defect with the Abiomed BVS 5000 ventricular assist device. J Thorac Cardiovasc Surg. 2003;126:2100-1.

4. Kshettry VR, Salerno CT, Bank AJ. Risk of left ventricular assist device as a bridge to heart transplant following postinfarction ventricular septal rupture. J Card Surg. 1997;12:93.

5. Meyns B, Vanermen H, Vanhaecke J, Sergeant P, Daenen W, Flameng W. Hemopump fails as bridge to transplantation in postinfarction ventricular septal defect. J Heart Lung Transplant. 1994;13: 1133 . 

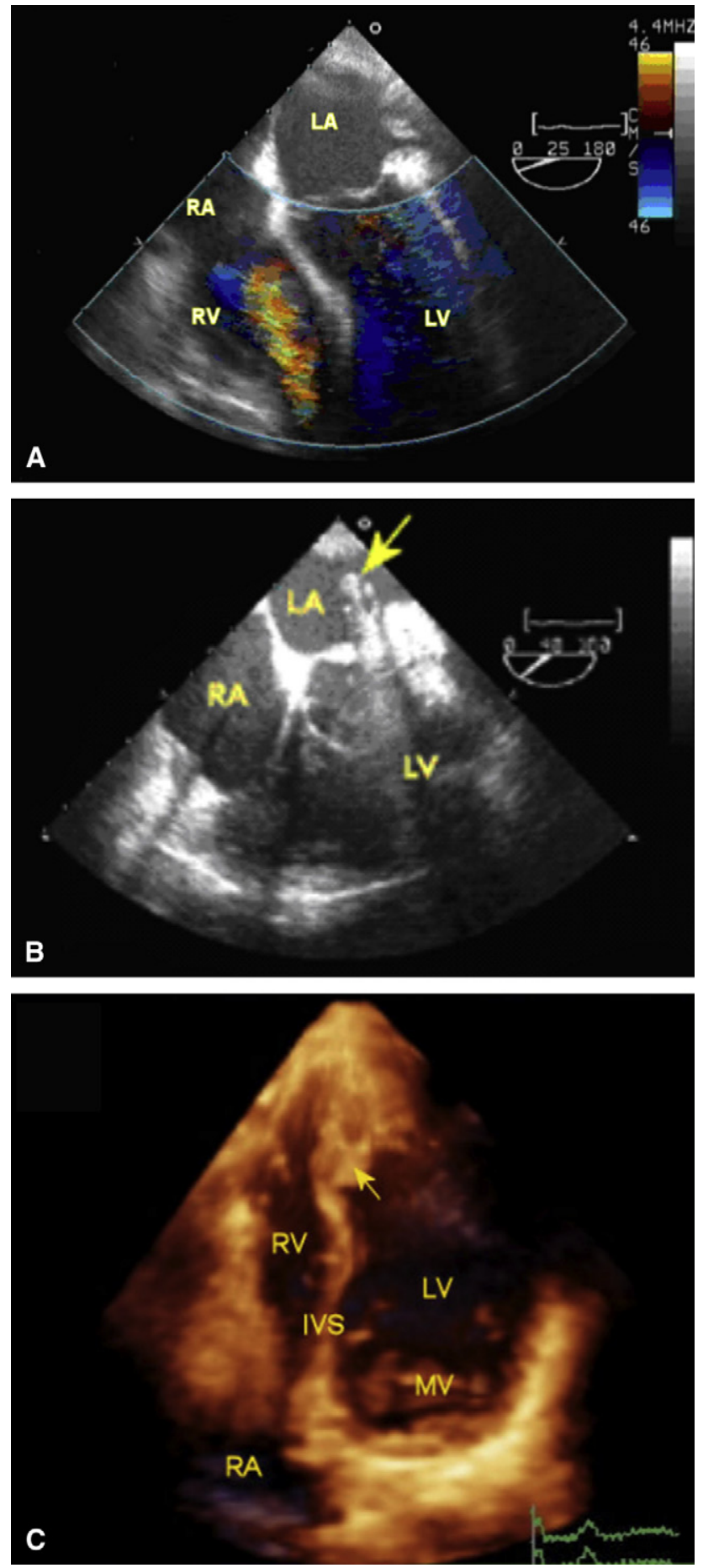

Figure 1. A, Preoperative 4-chamber midesophageal transesophageal echocardiography demonstrating significant left-to-right shunt. B, Preoperative 4-chamber midesophageal transesophageal echocardiography showing the tip of the inflow cannula (arrow) of the LVAD into the left atrium. C, One-year follow-up echocardiogram: Long-axis 3-dimensional echocardiogram demonstrating the left ventricular reconstruction using the bovine pericardial patch (arrow). LA, Left atrium; $R A$, right atrium; $R V$, right ventricle; $L V$, left ventricle; IVS, interventricular septum.
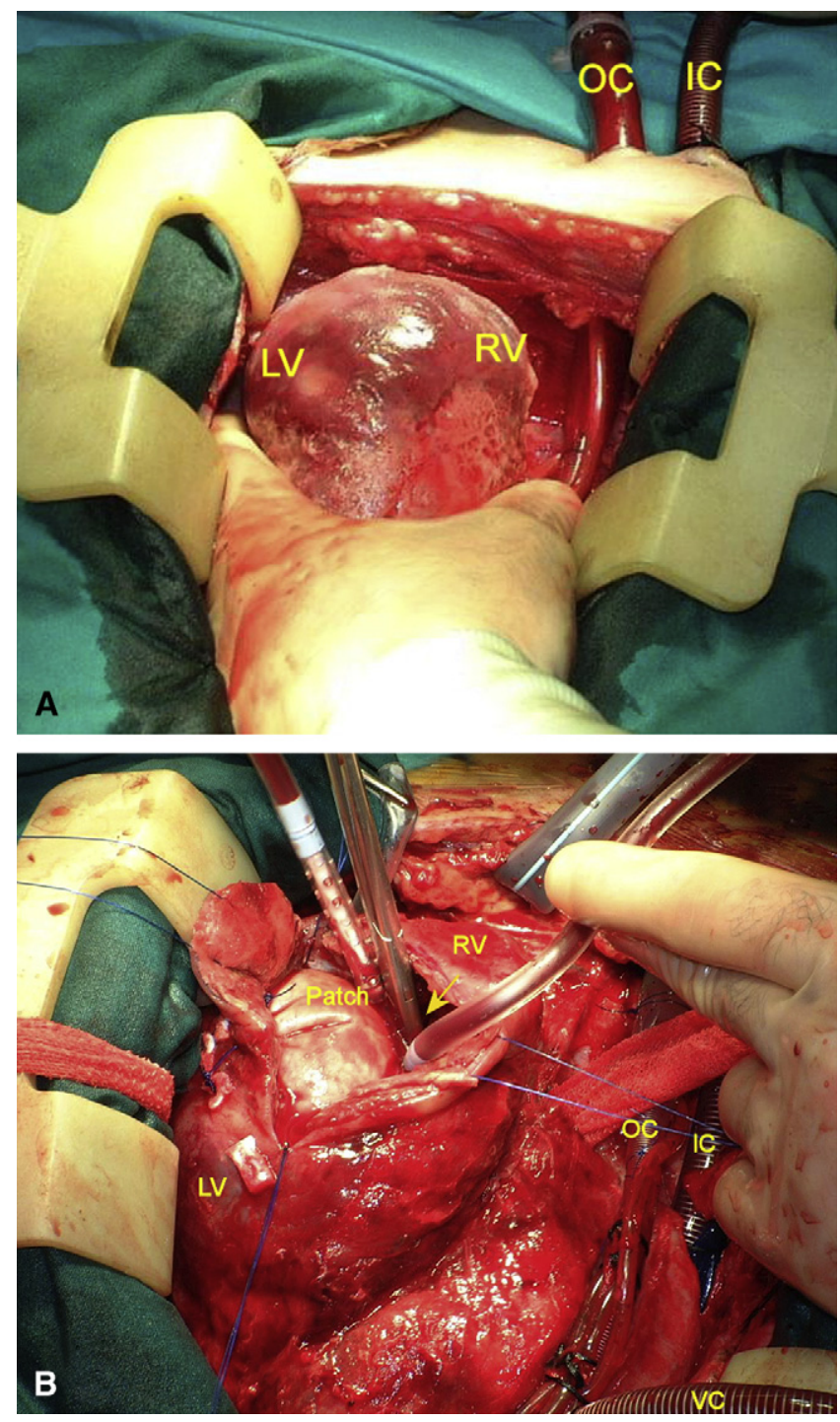

Figure 2. A, Extensive hematoma of the $L V$ and RV during the first operation. B, Bovine pericardial patch of the PVSD repair in the second operation with arrow showing a dissector with the tip inserted through the PVSD. IC, Inflow cannula; OC, outflow cannula; $L V$, left ventricle; $R V$, right ventricle; $V C$, venous cannula. 